Original

\title{
Use of aminoguanidine, a selective inducible nitric oxide synthase inhibitor, to evaluate the role of nitric oxide in periapical inflammation
}

\author{
Ali R. Farhad ${ }^{1)}$, Seyedmohammad Razavi ${ }^{2)}$, Sanaz Jahadi ${ }^{1)}$ and Masoud Saatchi ${ }^{1)}$ \\ ${ }^{1)}$ Department of Endodontics, Torabinejad Dental Research Center, School of Dentistry, \\ Isfahan University of Medical Sciences, Isfahan, Iran \\ ${ }^{2)}$ Department of Pathology, Torabinejad Dental Research Center, School of Dentistry, \\ Isfahan University of Medical Sciences, Isfahan, Iran
}

(Received 6 December 2010 and accepted 6 May 2011)

\begin{abstract}
The purpose of this study was to evaluate the effects of aminoguanidine (AG) as a selective inhibitor of inducible nitric oxide synthase (iNOS) on the degree of inflammatory response in periapical lesions in the canine teeth of cats. Root canals from 52 cat canine teeth were exposed to the oral cavity and sealed after 7 days. One day before pulp exposure, cats were administered either AG (experimental group) or normal saline (control group), which was continued on a daily basis until the day of sacrifice. Animals were sacrificed at 28 days after pulp exposure. Inflammatory response in the periapical zones was analyzed histologically. The degree of periapical inflammation in the AG group was significantly lower than that in the control group $(P<\mathbf{0 . 0 5})$. Selective iNOS inhibitors such as AG thus reduce the intensity of inflammatory responses in periapical lesions. (J Oral Sci 53, 225230, 2011)
\end{abstract}

Keywords: apical periodontitis; aminoguanidine; inflammation; nitric oxide; nitric oxide synthase.

Correspondence to Dr. Masoud Saatchi, Department of Endodontics, Torabinejad Dental Research Center, School of Dentistry, Isfahan University of Medical Sciences, Isfahan 81746-73461, Iran

Tel: +98-311-7922847

Fax: +98-311-6687080

E-mail: Saatchi@dnt.mui.ac.ir

\section{Introduction}

Apical periodontitis is a sequela to endodontic infection that manifests itself as the host defense response to microbial challenge emanating from the root canal system. It is viewed as a dynamic encounter between microbial factors and host defenses at the interface between infected radicular pulp and the periodontal ligament, which results in local inflammation and resorption of periapical hard tissues. Pulpal infection, which mainly involves gramnegative bacteria, may occur as a result of caries, restorations or trauma (1). Such infection first elicits an immune response in the dental pulp, which stimulates a secondary immune response to bacteria in the periapical region after total pulpal necrosis. This reaction represents a protective response to bacteria in the necrotic pulp and root canal system. Pulpal and periapical immune responses initially involve innate immunity, and adaptive immune elements are activated as responses become more chronic. Under these conditions, complex immunologic mechanisms that protect the pulp and periapical region, while causing host tissue destruction and mediating periapical bone resorption, are activated.

Free radicals are highly reactive molecules of either host or bacterial origin that can damage nearby cells. Nitric oxide (NO) may act as a pro-inflammatory or antiinflammatory mediator in human tissues. NO is a soluble gas, and depending on the site of production and the concentration produced, exerts several different biologic effects. It is synthesized by three distinct isoforms of nitric oxide synthase (NOS) (2). Neuronal and endothelial
\end{abstract}


isoforms of NOS are constantly produced in low amounts in the body. Inducible NOS (iNOS) generates high concentrations of NO upon stimulation by bacterial lipopolysaccharides and inflammatory cytokines such as IFN- $\gamma$, IL- $1 \beta$ or TNF- $\alpha$ (3). NO synthesized by iNOS has a distinct role in cellular processes, including the induction of apoptosis (4), inhibition of mitochondrial respiration (5) and regulation of oxidative phosphorylation, in addition to its cytotoxic effects on target cells (6).

Aminoguanidine (AG) is a bifunctional molecule comprising the guanido group from L-arginine linked to hydrazine, and was first described by Corbett et al. (7) as a selective inhibitor of iNOS. Misko et al. (8) showed that AG selectively inhibits iNOS without increasing blood pressure; AG was over 50 -fold more effective at inhibiting the enzymatic activity of iNOS than endothelial or neuronal isoforms of NOS (9).

The aim of this study was to evaluate the effects of AG as a selective inhibitor of iNOS on the degree of inflammation in periapical lesions of canine teeth from cats.

\section{Materials and Methods}

This study was approved by the Ethics Committee of the Isfahan University of Medical Sciences. For this study, the cat model was selected because of its availability, ease of handling and anesthetizing, and well-understood pulpal and periapical anatomy (10). Fifty-two canine teeth from 1-year-old male cats $(n=13)$ were used in this interventional experimental study, with all teeth having intact crowns and healthy periapical and periodontal tissues on clinical examination and pretreatment radiographs. Necessary vaccinations were performed for all experimental animals. General anesthesia was induced with $0.02 \mathrm{mg} / \mathrm{kg}$ intramuscular $2 \%$ acepromazine (Alfasan, Woerden, Holland) and $10 \mathrm{mg} / \mathrm{kg}$ intramuscular ketamine hydrochloride (Parke Davis, Courbevoie, France). Buccal infiltration of $2 \%$ lidocaine containing 1:100,000 epinephrine (Xylocaine, Dentsply Pharmaceutical, York, PA, USA) was injected at the apex. Maxillary and mandibular canines were isolated with rubber dams and pulp exposure was performed by removal of the $1 / 3$ coronal portions of the crown. The coronal areas of the root canals were enlarged using a \#1/4 round bur to the depth of the bur diameter. Working length was determined by inserting a \#15 file (Mani, Utsunomiya, Japan) and taking a radiograph. Pulp was removed using a barbed broach (Zipperer, Munich, Germany) with minimal damage to periapical tissues. Root canals were left exposed to the oral cavity for 7 days in order to allow microbial contamination, and access openings were sealed with amalgam (Kerr, Romulus, MI, USA).

\section{Drug treatments}

There were six animals in the control group and seven in the experimental group. Four canine teeth from each cat were used. The required amount $(25 \mathrm{mg} / \mathrm{kg})$ of $\mathrm{AG}$ hydrochloride (Sigma-Aldrich, St Louis, MO, USA) for each cat was dissolved in $2 \mathrm{ml}$ of sterile normal saline. In a preliminary study, it was confirmed that this concentration of AG was sufficient to block the synthesis of NO in serum without any harmful systemic effects. One day before pulp exposure, cats were given an intraperitoneal injection of either AG or normal saline (control group), and injections were continued on a daily basis until the day of sacrifice. Animals were sacrificed at 28 days after pulp exposure. Vital perfusion was performed so that periapical tissues became fixed before degeneration. Specimens were fixed in $10 \%$ neutral buffered formalin and demineralized in $7 \%$ nitric acid, and were subsequently dehydrated, embedded in paraffin and sectioned along the canines in the buccolingual plane for hematoxylin and eosin staining. Five 5- $\mu \mathrm{m}$ sections (separated by $50 \mu \mathrm{m}$ ), including the apex of canines and periapical bone, were prepared for each specimen. Histology of the periapical zones was analyzed by light microscopy (Carl Zeiss 452904-9901, Oberkachen, Germany) by an expert pathologist using a single-blind protocol. Stages of inflammation from 1 to 4 , as defined in Table 1, were used to score specimens. Inflammation scores of 3.00 and 4.00 were characterized by the presence of more inflammatory cells (indicating advanced inflammatory process), fewer fibroblasts (indicating limited repair process), bone and cementum resorption with granulation tissue formation, PDL degeneration, and focal areas of necrosis with abscess formation. Inflammation scores 1.00 and 2.00 were characterized by fewer inflammatory cells (indicating limited inflammatory process), more fibroblasts (indicating advanced repair process), intact bone and cementum, intact or widened PDL, and fibrous tissue formation. Mean inflammation scores in the two groups were compared by Mann-Whitney $U$ test. A probability value of $P<0.05$ was considered to indicate a significant difference between the groups.

\section{Results}

All cats tolerated the surgical procedures throughout the study period. Treated teeth did not show any evidence of swelling or sinus tract. Mean scores for inflammation in the AG and control groups were $2.6786( \pm 0.6118)$ and 3.1250 ( \pm 0.7974$)$, respectively. Distribution of inflammation scores within the AG and control groups is shown in Table 2.The majority (83.3\%) of control samples were distributed between inflammation scores 3.00 and 4.00, while the majority (92.9\%) of AG samples were distributed 
Table 1 Stages of inflammation

\begin{tabular}{llll}
\hline $\begin{array}{l}\text { Stage I } \\
\text { (score 1) }\end{array}$ & $\begin{array}{l}\text { Stage II } \\
\text { (score 2) }\end{array}$ & $\begin{array}{l}\text { Stage III } \\
\text { (score 3) }\end{array}$ & $\begin{array}{l}\text { Stage IV } \\
\text { (score 4) }\end{array}$ \\
\hline No inflammatory response & $\begin{array}{l}<\text { Macrophages \& } \\
\text { plasma cells }\end{array}$ & $\begin{array}{l}10-25 \text { Macrophages \& } \\
\text { plasma cells }\end{array}$ & $\begin{array}{l}\text { >25 Macrophages \& } \\
\text { plasma cells }\end{array}$ \\
$>30$ Fibroblasts & 10-30 Fibroblasts & 5-9 Fibroblasts & 1-4 Fibroblasts \\
Mature fibrous tissue with & Immature fibrous tissue & Granulation tissue & Focal areas of necrosis \\
a lot of collagen & with little collagen & & \\
PDL intact & PDL widening & PDL degeneration & PDL degeneration \\
Cementum intact & Cementum intact & Cementum resorption & Abscess \\
Bone intact & Bone intact & Bone resorption & Abscess \\
\hline
\end{tabular}

between inflammation scores 2.00 and 3.00. The difference between the experimental and control groups was statistically significant $(P=0.017)$. Thus, $\mathrm{AG}$ as a selective iNOS inhibitor significantly reduced the degree of periapical inflammation in cats.

\section{Discussion}

Basic science researchers have studied the role of NO in inflammatory diseases such as rheumatoid arthritis (6), diabetes (7) and bone remodeling (11). In addition, researchers in dentistry have evaluated the function of NO in the inflammatory processes of the oral mucosa (12), periodontal tissues $(13,14)$, pulp (15) and periapical areas (16). Cytokines and reactive intermediates of oxygen and nitrogen are frequently found at inflammatory sites, but their function in pulp and periapical tissues is not yet fully understood. Specifically, NO exhibits a dual function in inflammatory conditions; under some circumstances, it inhibits inflammation, and in others, it is an effective proinflammatory factor (17).

As this dual function of $\mathrm{NO}$ can exist in apical periodontitis, a better understanding of the role of $\mathrm{NO}$ in the pathophysiology of inflammation in periapical lesions may be helpful in future pharmacological interventions. The bulk of previous studies have only addressed the presence or absence of NO in inflamed pulp, granulomas and periapical cysts; however, as the presence or absence of a substance in a specific tissue does not necessarily indicate its role, the exact function of NO in inflammatory processes of teeth and surrounding tissues is poorly understood and remains controversial. Thus, to obtain a clearer picture of the complex inflammatory processes in the periapical area, the present animal model was designed to investigate the role of $\mathrm{NO}$ in periapical lesions.

Kawanishi et al. (15) evaluated the anti-inflammatory effects of an iNOS-specific inhibitor $(1400 \mathrm{~W})$ on experimentally induced rat pulpitis in a similarly designed experiment. Their results, which were consistent with our
Table 2 Distribution of inflammation scores (count and percentage) in Aminoguanidine (AG) and control groups

\begin{tabular}{lcc}
\hline \multirow{2}{*}{ Inflammation Score } & \multicolumn{2}{c}{ Groups } \\
\cline { 2 - 3 } & Control & $\mathrm{AG}$ \\
\hline 1.00 & 1 & 1 \\
& $4.2 \%$ & $3.6 \%$ \\
2.00 & 3 & 8 \\
& $12.5 \%$ & $28.6 \%$ \\
3.00 & 12 & 18 \\
& $50.0 \%$ & $64.3 \%$ \\
4.00 & 8 & 1 \\
\multirow{2}{*}{ Total } & $33.3 \%$ & $3.6 \%$ \\
& 24 & 28 \\
& $100.0 \%$ & $100.0 \%$ \\
\hline
\end{tabular}

findings, suggested that $\mathrm{NO}$ is responsible for the infiltration of immunocompetent cells in the development of pulpitis. Investigations by da Silva et al. (18), Law et al. (19), Di Nardo Di Maio et al. (20) and Fan et al. (21) all showed greater concentrations of NOS enzymes in inflamed zones in comparison to noninflamed areas of the pulp. The results of the present study are similar to the observations in these experiments. Yasuhara et al. (22) suggested that NO is involved in the regulation of pulp cell growth, apoptosis and mineralization. According to Min et al. (23), NO is able to induce IL-8 expression via the mitogenactivated protein kinase (MAPK) and nuclear factor $-\kappa \beta$ $(\mathrm{NF}-\kappa \beta)$ pathways, which play important roles in the inflammatory responses of pulpal and periapical lesions.

Expression of iNOS has been investigated in periapical granulomas and cysts by numerous investigators (24-27). Hama et al. (28) proposed a mechanism regarding the role of $\mathrm{NO}$ in the progression of periapical inflammation; they showed that inflammatory cells such as macrophages express receptor for advanced glycation endproduct (RAGE) in periapical granulomas, which infiltrates around 
cells producing iNOS. Binding of advanced glycation endproduct (AGE) with RAGE accelerates vascular disease and induces synthesis and secretion of pro-inflammatory cytokines. The results of the present study differ from the findings of Fukada et al. (29). They evaluated the role of $\mathrm{NO}$ in bone loss in bacterially induced apical periodontitis using iNOS-deficient mice. They reported that iNOSdeficient mice exhibited greater inflammatory cell recruitment and osteolytic lesions than normal mice. The difference in these results may be due to: 1) AG, which, in addition to being an iNOS selective inhibitor, has antioxidant properties, and this may have reduced free radicals and induced anti-inflammatory effects $(11) ; 2$ ) in our study, iNOS concentrations were reduced pharmacologically, but in the Fukada et al. study, iNOS was completely blocked; and 3) mouse teeth and surrounding tissues are structurally different from cat teeth.

Most of the studies investigating the role of $\mathrm{NO}$ in
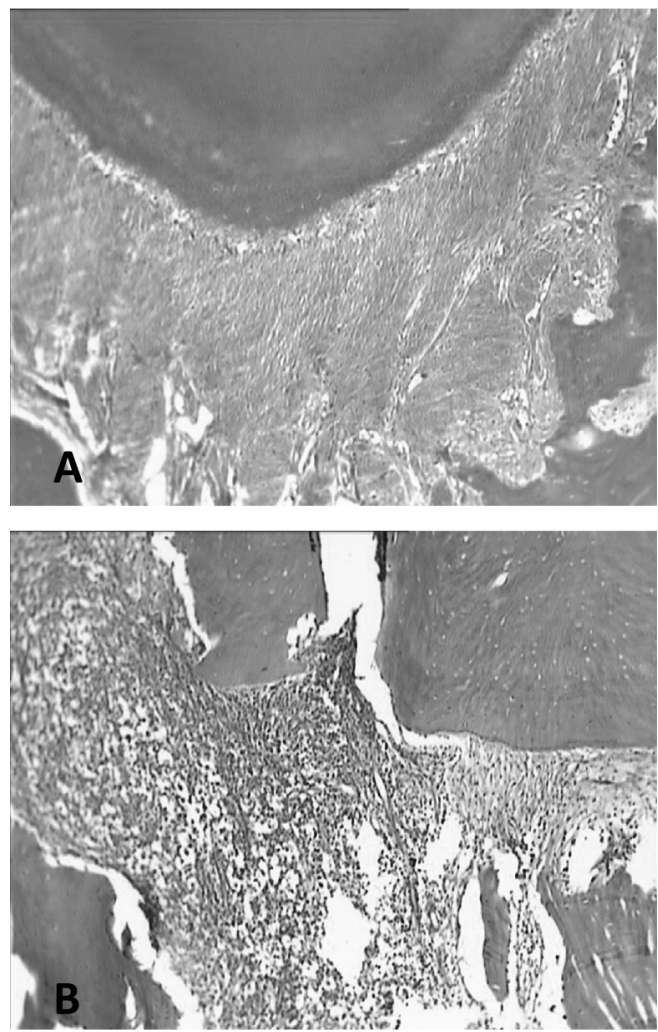

Fig. 1 (A) Histological view of the AG group after 4 weeks showing minimal inflammation corresponding to an inflammation score of $2.00(\mathrm{H} \& \mathrm{E} ; \times 100)$.

(B) Histological view of the control group after 4 weeks showing severe inflammation corresponding to an inflammation score of $4.00(\mathrm{H} \& \mathrm{E} ; \times 100)$. inflammatory processes of the periodontium have shown that $\mathrm{NO}$ is a pro-inflammatory mediator that can cause alveolar bone resorption (12-14). Di Paola et al. (30) reported that when $\mathrm{AG}$ was used to reduce the NO concentration in rats with induced marginal periodontitis, the density of inflammatory cells and alveolar bone resorption decreased. The results of these studies support the findings of our research.

In this study, the root canals of both the control and AG groups were contaminated with oral microbial flora, and the only difference between the two groups was the AG drug intervention in the experimental group. Kakehashi et al. (31) established the role of microbes in pulp and periapical pathosis. The damage to host tissues from microbial infection of the root canal system is the result of: i) direct damage from proteolytic and noxious waste products of microorganisms; and ii) host inflammatory/immune response that leads to tissue destruction such as periradicular bone. As the inflammatory process advances from stage I to stage IV, typical forms of chronic apical periodontitis develop, accompanied by periapical granuloma and possible micro-abscess formation. Humoral and cellular immunity are activated to limit further inflammation and to initiate tissue repair (32). The histopathological feature of periapical lesions is a dense infiltration of immunocompetent cells such as neutrophils, macrophages, lymphocytes, plasma cells, giant cells, NK cells and mast cells. Neutrophils and macrophages are the first line of defense in periapical lesions. These defensive cell types are involved in cell-mediated innate immunity that phagocytose microorganisms, dead cells and debris. $\mathrm{T}$ and $\mathrm{B}$ cells play an important role in antigen-specific immune response and are the predominant cell type in human periapical lesions. In addition, at the lesion periphery, plasma cells and lymphocytes are observed (32). Inflammatory mediators including cytokines, antibodies, growth factors and arachidonic acid metabolites are involved in the initiation and maintenance of inflammation. These inflammatory mediators have specific and overlapping functions and are directly or indirectly involved in periradicular lesion formation and establishment (32).

In conclusion, the present study provides in vivo evidence regarding the role of $\mathrm{NO}$ in the progression of the inflammatory process in the periapical area. The results of this study support the use of iNOS-selective inhibitors such as AG to reduce the inflammatory intensity in periapical lesions (Fig. 1). As NO has other biological functions, it is likely that AG has other systemic effects, and there have been few dentistry studies regarding the processes mediated by $\mathrm{AG}$ and $\mathrm{NO}$; further research is 
therefore required to comprehensively evaluate the role of AG on inflammatory processes. Future research can focus on different concentrations of $\mathrm{AG}$, the role of $\mathrm{AG}$ on the healing of periapical lesions and its mechanism of action. In addition, the effects of iNOS-selective promoters and other iNOS-selective inhibitors on the inflammatory process should be evaluated.

\section{Acknowledgments}

The authors wish to thank Dr. M. Minaiyan of the Department of Pharmacology and Toxicology, Isfahan University of Medical Sciences for his assistance.

\section{References}

1. Sundqvist G (1992) Ecology of the root canal flora. J Endod 18, 427-430.

2. Chartrain NA, Geller DA, Koty PP, Sitrin NF, Nussler AK, Hoffman EP, Billiar TR, Hutchinson NI, Mudgett JS (1994) Molecular cloning, structure, and chromosomal localization of the human inducible nitric oxide synthase gene. J Biol Chem 269, 6765-6772.

3. Snyder SH, Bredt DS (1992) Biological roles of nitric oxide. Sci Am 266, 68-71, 74-77.

4. Tunbridge AJ, Stevanin TM, Lee M, Marriott HM, Moir JW, Read RC, Dockrell DH (2006) Inhibition of macrophage apoptosis by Neisseria meningitidis requires nitric oxide detoxification mechanisms. Infect Immun 74, 729-733.

5. Hagen T, Taylor CT, Lam F, Moncada S (2003) Redistribution of intracellular oxygen in hypoxia by nitric oxide: effect on HIF1 $\alpha$. Science 302, 19751978.

6. Nisoli E, Clementi E, Paolucci C, Cozzi V, Tonello C, Sciorati C, Bracale R, Valerio A, Francolini M, Moncada S, Carruba MO (2003) Mitochondrial biogenesis in mammals: the role of endogenous nitric oxide. Science 299, 896-899.

7. Corbett JA, Tilton RG, Chang K, Hasan KS, Ido Y, Wang JL, Sweetland MA, Lancaster JR Jr, Williamson JR, McDaniel ML (1992) Aminoguanidine, a novel inhibitor of nitric oxide formation, prevents diabetic vascular dysfunction. Diabetes 41, 552-556.

8. Misko TP, Moore WM, Kasten TP, Nickols GA, Corbett JA, Tilton RG, McDaniel ML, Williamson JR, Currie MG (1993) Selective inhibition of the inducible nitric oxide synthase by aminoguanidine. Eur J Pharmacol 233, 119-125.

9. Corbett JA, McDaniel ML (1996) The use of aminoguanidine, a selective iNOS inhibitor, to evaluate the role of nitric oxide in the development of autoimmune diabetes. Methods 10, 21-30.

10. Torabinejad M, Bakland LK (1978) An animal model for the study of immunopathogenesis of periapical lesions. J Endod 4, 273-277.

11. Collin-Osdoby P, Rothe L, Bekker S, Anderson F, Osdoby P (2000) Decreased nitric oxide levels stimulate osteoclastogenesis and bone resorption both in vitro and in vivo on the chick chorioallantoic membrane in association with neoangiogenesis. $\mathrm{J}$ Bone Miner Res 15, 474-488.

12. Hirose M, Ishihara K, Saito A, Nakagawa T, Yamada S, Okuda K (2001) Expression of cytokines and inducible nitric oxide synthase in inflamed gingival tissue. J Periodontol 72, 590-597.

13. Gaspirc B, Masera A, Skaleric U (2002) Immunolocalization of inducible nitric oxide synthase in localized juvenile periodontitis patients. Connect Tissue Res 43, 413-418.

14. Leitão RF, Ribeiro RA, Chaves HV, Rocha FA, Lima V, Brito GA (2005) Nitric oxide synthase inhibition prevents alveolar bone resorption in experimental periodontitis in rats. J Periodontol 76, 956-963.

15. Kawanishi HN, Kawashima N, Suzuki N, Suda H, Takagi M (2004) Effects of an inducible nitric oxide synthase inhibitor on experimentally induced rat pulpitis. Eur J Oral Sci 112, 332-337.

16. Lin SK, Kok SH, Lin LD, Wang CC, Kuo MY, Lin CT, Hsiao M, Hong CY (2007) Nitric oxide promotes the progression of periapical lesion via inducing macrophage and osteoblast apoptosis. Oral Microbiol Immunol 22, 24-29.

17. Hargreaves KM, Goodis HE (2002) Seltzer and Bender's dental pulp. 3rd ed, Quintessence, Chicago, 262-263.

18. da Silva LP, Issa JP, Del Bel EA (2008) Action of nitric oxide on healthy and inflamed human dental pulp tissue. Micron 39, 797-801.

19. Law AS, Baumgardner KR, Meller ST, Gebhart GF (1999) Localization and changes in NADPHdiaphorase reactivity and nitric oxide synthase immunoreactivity in rat pulp following tooth preparation. J Dent Res 78, 1585-1595.

20. Di Nardo Di Maio F, Lohinai Z, D'Arcangelo C, De Fazio PE, Speranza L, De Lutiis MA, Patruno A, Grilli A, Felaco M (2004) Nitric oxide synthase in healthy and inflamed human dental pulp. J Dent Res 83, 312-316.

21. Fan W, Huang F, Li C, Qu H, Gao Z, Leng S, Li D, $\mathrm{He} H$ (2009) Involvement of NOS/NO in the 
development of chronic dental inflammatory pain in rats. Brain Res Rev 59, 324-332.

22. Yasuhara R, Suzawa T, Miyamoto Y, Wang X, Takami M, Yamada A, Kamijo R (2007) Nitric oxide in pulp cell growth, differentiation, and mineralization. J Dent Res 86, 163-168.

23. Min KS, Kim HI, Chang HS, Kim HR, Pae HO, Chung HT, Hong SH, Shin HI, Hong CU, Lee SK, Kim EC (2008) Involvement of mitogen-activated protein kinases and nuclear factor- $\kappa \mathrm{B}$ activation in nitric oxide-induced interleukin-8 expression in human pulp cells. Oral Surg Oral Med Oral Pathol Oral Radiol Endod 105, 654-660.

24. Takeichi O, Saito I, Hayashi M, Tsurumachi T, Saito T (1998) Production of human-inducible nitric oxide synthase in radicular cysts. J Endod 24, 157160.

25. Suzuki T, Kumamoto H, Ooya K, Motegi K (2002) Expression of inducible nitric oxide synthase and heat shock proteins in periapical inflammatory lesions. J Oral Pathol Med 31, 488-493.

26. Hama S, Takeichi O, Hayashi M, Komiyama K, Ito K (2006) Co-production of vascular endothelial cadherin and inducible nitric oxide synthase by endothelial cells in periapical granuloma. Int Endod J 39, 179-184.
27. Kabashima H, Nagata K, Maeda K, Iijima T (1998) Interferon-gamma-producing cells and inducible nitric oxide synthase-producing cells in periapical granulomas. J Oral Pathol Med 27, 95-100.

28. Hama S, Takeichi O, Saito I, Ito K (2007) Involvement of inducible nitric oxide synthase and receptor for advanced glycation end products in periapical granulomas. J Endod 33, 137-141.

29. Fukada SY, Silva TA, Saconato IF, Garlet GP, AvilaCampos MJ, Silva JS, Cunha FQ (2008) iNOSderived nitric oxide modulates infection-stimulated bone loss. J Dent Res 87, 1155-1159.

30. Di Paola R, Marzocco S, Mazzon E, Dattola F, Rotondo F, Britti D, De Majo M, Genovese T, Cuzzocrea S (2004) Effect of aminoguanidine in ligature-induced periodontitis in rats. J Dent Res 83, 343-348.

31. Kakehashi S, Stanley HR, Fitzgerald RJ (1965) The effects of surgical exposures of dental pulps in germ-free and conventional laboratory rats. Oral Surg Oral Med Oral Pathol 20, 340-349.

32. Takahashi K (1998) Microbiological, pathological, inflammatory, immunological and molecular biological aspects of periradicular disease. Int Endod J 31, 311-325. 